\title{
Erratum
}

\section{Erratum to "Traumatic Brain Injury in Children under Age 24 Months : Analysis of Demographic Data, Risk Factors, and Outcomes of Post-traumatic Seizure" by Yoon SY, et al. (J Korean Neurosurg Soc 60 : 584-590, 2017)}

https://doi.org/10.3340/jkns.2016.0707.008

In this article by Yoon SY et al., in the Table 7, the number of poor outcome in patient with subdural hematoma was given incorrectly. It should have read "1" instead of " 25 ".

Corrected Table 7 is as follows;

Table 7. Univariate analysis of risk factors for poor outcomes*

\begin{tabular}{lccc} 
Diagnosis & $\begin{array}{c}\text { Number of } \\
\text { patients }\end{array}$ & $\begin{array}{c}\text { Number } \\
\text { of poor } \\
\text { outcomes }\end{array}$ & p-value \\
\hline $\begin{array}{l}\text { Focal contusional } \\
\text { hemorrhage }\end{array}$ & 7 & 5 & 0.099 \\
Traumatic ICH & 4 & 2 & 0.032 \\
Acute subdural hematoma & 26 & 1 & 0.377 \\
Hydrocephalus & 2 & 1 & 0.161 \\
Glasgow coma scale score & & & 0.000 \\
13-15 & 48 & 0 & \\
$8-12$ & 8 & 2 & \\
$3-7$ & 4 & 3 & \\
Age & & 1 & \\
$0-5$ & 26 & 1 & \\
$6-11$ & 22 & 2 & \\
$12-17$ & 6 & 1 & \\
$18-23$ & 6 & & \\
\hline
\end{tabular}

*Factors with p-values larger than 0.5 were not included in the table.

$\mathrm{ICH}$ : intracerebral hematoma 